\title{
Artículos \\ Eduardo Urbina Ayala. Oralidad y poesía desde el exilio
}

\author{
Eduardo Urbina Ayala. Orality and Poetry in Exile
}

\author{
Fecha de recepción: 12/10/2020 \\ Fecha de aceptación: 11/01/2021 \\ Fecha de publicación: 03/05/2021
}

https://doi.org/10.48102/if.2021.v1.n1.148

\author{
Rolan Eduardo Soto Lopez* \\ rolanhisto@gmail.com \\ ORCID: https://orcid.org/0000-0002-7551-6322 \\ Maestrante en Historia \\ Centro de Investigaciones y Estudios Superiores en Antro- \\ pología Social (CIESAS-Peninsular) \\ México
}

\section{Resumen}

El fenómeno del exilio ha sido una constante en América Latina. Se ha constituido en una forma de hacer política tanto para regímenes autoritarios como para los sistemas de gobierno democráticos. Las transiciones a la democracia no han implicado el abandono de este recurso de exclusión institucionalizada. Este artículo indaga sobre el potencial de la historia oral y la palabra escrita como una fuente que visibiliza la condición del desterrado. Para ello se analizan cualitativamente las entrevistas realizadas a Eduardo Urbina y la poesía que escribió desde el país de acogida. Los resultados obtenidos muestran la viabilidad de la historia oral y la poesía para reconstruir las dinámicas del exilio contemporáneo.

\footnotetext{
* Licenciado en Historia por la Universidad Nacional Autónoma de Honduras. Maestrante en Historia por el CIESAS-Peninsular. Sus líneas de investigación son el exilio político hondureño en el siglo XX, el exilio centroamericano y la dictadura de Tiburcio Carías Andino.
} 


\title{
Palabras clave
}

Exilio, exclusión institucionalizada, historia oral, poesía, Eduardo Urbina.

\section{Abstract}

Exile has been a constant in twentieth-century Latin American countries. Exile has even had impact in policy-making both in authoritarian and democratic regimes. It has been constituted in a form to make policy for regimes as much authoritarian as for the democratic systems of government. This article investigates oral history and written word as sources to highlight exile as an exclusionary condition. The paper makes use of interviews and poetry by Eduardo Urbina and shows the dynamics of contemporary exile.

\section{Keywords}

Exile, institutionalized exclusion, oral history, poetry, Eduardo Urbina.

\section{Introducción}

\author{
A mi por suerte me queda voz y \\ hasta que esa voz no la callen \\ yo voy a seguir denunciándolos. \\ Más allá de las actuaciones existen \\ las palabras y si las palabras están plasmadas, \\ perduran. \\ Eduardo Urbina
}

Hablar de Honduras bajo el espectro de la represión, la violencia y la falta de respeto a los derechos humanos exige referirse al exilio político. Desde la cuarta década del siglo XVIII, Francisco Morazán huyó a Panamá. Para el siglo XX, la dinámica del exilio hondureño tuvo su punto álgido durante la dictadura de Tiburcio Carías Andino (1933-1949). En este periodo, políticos, intelectuales y profesionales de la salud salieron del país y crearon comunidades en México, Costa Rica, El Salvador y Panamá. El exilio como constante se manifiesta en el caso de Eduardo Urbina Ayala, hondureño exiliado en Costa Rica desde el 11 de diciembre de 2017 hasta la actualidad. A través de este estudio, se acude a la voz del sujeto para lograr reconstruir su experiencia. El destierro de Urbina permite dar cuenta de una dinámica más amplia: el golpe de Estado de 2009 en Honduras y la crisis política que se agudizó en 2017 y que continúa hasta la actualidad. La temática y el abor- 
daje son justificados por la necesidad de recuperar las múltiples voces de las víctimas, así como por la puesta en escena de la imperiosa necesidad del reclamo por la justicia social y el respeto a los derechos políticos y humanos. Se visibiliza el caso de Urbina como una muestra de la resistencia y la militancia, que, por venir de otro espacio, no deja de ser efectiva.

Para entender el contexto de crisis política en Honduras y la violencia de la que Eduardo Urbina fue y es víctima, es pertinente hacer un pequeño balance de los hechos desde 2009 hasta la actualidad. Analistas políticos, organismos internacionales y sociedad civil presentan un diagnóstico nada esperanzador. Por ejemplo, el analista político Rolando Sierra (2019) considera que el golpe de Estado de 2009 ha llevado a Honduras hacia una "crisis continuada":

Se observa que su sociedad no ha logrado entrar en una senda de consolidación democrática. El país enfrenta déficits institucionales y sociales significativos en el marco de una crisis continuada que parece no tener salida. Las elecciones de 2017 evidenciaron el agotamiento del sistema y del modelo electoral vigente desde 2006, y la cuestión de la reelección sigue sin estar resuelta. (p. 17)

La crisis se expresa en la pobreza, la desigualdad, la violencia y la creciente migración. Todo esto ha llevado, según el autor, a una "creciente conflictividad". La sociedad hondureña, en medio de la incertidumbre en la que se ve envuelta, demanda transparencia, reclama ante la impunidad, pide la rebaja en el precio de los combustibles y mejores condiciones para lograr el acceso a la educación y a la salud. No se puede negar el paso del bipartidismo tradicional al pluralismo partidario. Sin embargo, para Sierra, falta mucho para la consolidación democrática. Otros autores también comparten el criterio:

El periodo post-golpe se caracteriza por el predominio político del Partido Nacional y un proceso paulatino de acumulación y concentración de poder alrededor de la figura de Juan Orlando Hernández. Para ello se distorsionó el equilibrio entre los tres poderes del Estado y se subordinó la institucionalidad y la legalidad a la intolerancia y el autoritarismo del poder gubernamental. Ello va de la mano con la 
expansión sistemática de redes de corrupción y clientelismo. (Waxenecker, 2019, p. 118)

Actualmente, presos políticos, criminalizados y perseguidos son víctimas del autoritarismo. El clima de represión, violencia política e intolerancia a la disidencia provocó el destierro de Eduardo Urbina. Esta investigación tiene como objetivo dar a conocer, interpretar y visibilizar la condición del exiliado recurriendo a la historia oral; para estos fines recurre a la experiencia de Eduardo Urbina Ayala. La investigación nació en 2018 como producto final integrador del Seminario Represión, Derechos Humanos y exilios en perspectiva comparada de la Cátedra CLACSO, coordinado por Silvia Jensen de la Universidad del Sur de Argentina.

Para el año del seminario, ${ }^{1}$ había pasado poco tiempo de la reelección presidencial en Honduras y las consecuentes manifestaciones y protestas del pueblo hondureño. Algunas consecuencias se expresaron en la persecución y la criminalización de la que Eduardo Urbina fue víctima. Conocía de cerca el caso debido a que Urbina fue mi compañero de clases en la carrera de Historia en la Universidad Nacional Autónoma de Honduras (UNAH). El panorama general propició la atención en su caso. Las entrevistas se realizaron en ese contexto de crisis política. Ante la imposibilidad de verlo personalmente, recurrí a la entrevista por llamada telefónica, una forma de producir fuentes orales. La entrevista a profundidad se llevó a cabo un 21 de octubre de 2018. El testigo se encontraba en San José, Costa Rica. Me interesaba conocer las dimensiones tanto política como existencial del exilio. Así, lo que se presenta a continuación se alimenta de categorías analíticas como la represión, los derechos humanos, el testimonio y la palabra escrita. Estas vías teóricas y metodológicas han sido empleadas constantemente en el Cono Sur.

Es necesario acotar que la constitución de espacios académicos en Latinoamérica para los estudios del exilio son recientes. El mejor ejemplo son las Jornadas de Trabajo sobre Exilios Políticos del Cono Sur en el siglo XX, surgida a raíz de las Jornadas de presentación de proyectos Exilio y Política, realizadas en agosto de 2010 en la Universidad Nacional de La

1 Un especial agradecimiento al historiador hondureño Óscar Gerardo Zelaya Garay; sus comentarios al borrador de este escrito midieron el potencial de la propuesta y motivaron su publicación. 
Plata. La primera jornada se centró en la circulación y conocimiento de los trabajos que actualmente se están desarrollando en distintos ámbitos y unidades académicas sobre los procesos de exilios políticos que afectaron a Brasil, Argentina, Bolivia, Chile, Paraguay y Uruguay durante la segunda mitad del siglo XX. ${ }^{2}$ Hay trabajos que problematizan memorias del exilio, los exilios de los intelectuales; otros que analizan políticas estatales de exilio y retorno, que estudian problemas de represión. Investigadores como Sznajder y Roniger (2013) han estudiado el exilio y el destierro en América Latina desde una perspectiva comparada y de larga duración. Melgar Bao (2018) se ha concentrado en el populismo peruano e indoamericano, tomando como centro su exilio en México entre los años 1934 y 1940. Soledad Lastra (2016) estudia las políticas de los gobiernos de Argentina y de Uruguay en los años ochenta para el retorno y recepción de sus exiliados políticos.

Para Centroamérica no se puede hablar de un espacio académico similar al del Cono Sur; sin embargo, algunos investigadores se han interesado por el tema. Laura Moreno (2013) investigó el exilio nicaragüense en México; su trabajo propone observar a los perseguidos políticos a través de los documentos confidenciales que generaron los organismos de seguridad mexicanos. Guadalupe Rodríguez de Ita (2001) diserta sobre los guatemaltecos en México, activistas opositores y sus luchas desde el destierro, así como sus deseos de regresar al país de origen. El caso salvadoreño es tratado por Monterrosa (2019) a partir de una hoja volante en la que estudia los "visos de la oposición en el exilio"; según este autor,

el manifiesto es relevante por dos razones: primero, porque cita la matanza de 1932 cuando el silencio reinaba al respecto y, segundo, porque establece los parámetros con los que la izquierda interpretó el martinato. Estos opositores, versados en la política salvadoreña y atentos al quehacer del régimen, lanzaron críticas mordaces. (p. 95)

En la agenda historiográfica hondureña, el exilio ha sido analizado por Argueta (2008), quien considera que, "al calor de los acontecimientos de 1944, la caída del dictador salvadoreño Hernández Martínez y su colega Jorge Ubico en Guatemala, permitieron reactivar la oposición en el exilio"

2 Se puede consultar el sitio oficial de este espacio académico, a través del que se difunde todo lo relacionado a las Jornadas: http://jornadasexilios.fahce.unlp.edu.ar/. 
(pp. 280-281). El autor elabora una pequeña síntesis sobre la actividad de los hondureños asentados en Centroamérica y México.

Este recuento historiográfico permite ver las vías que ha tomado el estudio de las migraciones forzadas y, principalmente, el exilio en América Latina desde su dimensión política hasta su dimensión sociocultural, desde las acciones estatales hasta las experiencias individuales. Esta última categoría, expresada a través del testimonio de Eduardo Urbina, adquiere especial interés en nuestro caso. En esta investigación, su voz es considerada un eco del actor, testigo y víctima. La centralidad en el actor da cuenta de un contexto amplio de represión en el espacio hondureño bajo el autoritarismo. El testimonio, tanto oral como escrito, denuncia el estatus de los derechos humanos en Honduras.

En un primer momento, se presenta el perfil de Eduardo Urbina y su militancia. Después se abordan las circunstancias que generó el golpe de Estado de Honduras en 2009 y la persecución a Urbina en 2017. En el apartado "Voz y palabra escrita. Las armas de denuncia desde el exilio", se reconstruye la experiencia del exiliado, tanto en su dimensión política como existencial, a través del testimonio oral y escrito. Y, finalmente, se presentan conclusiones y hallazgos que abren el debate.

\section{Eduardo Urbina Ayala: un objetivo del aparato represivo}

¿Quién es Eduardo Urbina? ¿Qué representó y representa para el régimen que lo expulsó? Su vida política es sintetizada por la siguiente cronología. Las interrogantes enunciadas serán contestadas a profundidad al momento de presentar su testimonio.

Urbina recuerda su idílica infancia y parte de su juventud: "solía salir en bicicleta, disfrutaba mucho jugar baloncesto e ir a conciertos" (E. Urbina, comunicación personal, 3 de enero de 2020). Nació el 4 de agosto de 1995 en Tegucigalpa, capital de Honduras. Su padre era capitalino, y, su madre, de la Costa Norte hondureña: "nací y crecí en el seno de una familia no tan tradicional en su configuración, con raíces campesinas y rurales muy marcadas. La crianza que me dio mi abuela, mi padre y mi tía fue una combinación del ajetreo de la vida en cuidad y las tradiciones y recuerdos nostálgicos de la vida en el campo" (E. Urbina, comunicación personal, 3 de enero de 2020). Hasta 2017, vivió junto a su familia en la zona habitacional Cerro Grande, aproximadamente a tres kilómetros del Centro de Tegucigalpa. 
Sus años de formación primaria y secundaria trascurrieron en las aulas de la Saint Mary's Episcopal School, de donde egresó en 2013. Acto seguido, ingresó a la carrera de Biología de la UNAH, pero sus intereses académicos lo dirigieron a la carrera de Historia. Su vida también estuvo marcada por el involucramiento social a través de voluntariados en distintas ONG: "desempeñé labores como facilitador, encargado de redes sociales y hasta de encuestador" (E. Urbina, comunicación personal, 3 de enero de 2020).

En cuanto a su militancia, desde 2009 hasta la actualidad, Eduardo Urbina Ayala forma parte del Frente Nacional Resistencia Popular. Entre 2010 y 2011 fue miembro del Movimiento Patriótico en Resistencia. Desde 2011 forma parte de la organización política Los Necios y del Partido Libertad y Refundación. Izquierdas socialistas de Honduras es otra organización en la que Urbina tiene participación desde 2011. No de menos importancia es su beligerancia en la Mesa Estudiantes Indignados y el Movimiento Estudiantil Universitario (MEU). Finalmente, de 2016 a 2017 fue integrante del Grupo Cultural Coquimbo.

Su trayectoria da cuenta del activismo político que tendría tantas repercusiones en su vida. Para algunos autores, se debe tomar en cuenta al exiliado como "actor, testigo y víctima" (Jensen, 2011). Las tres facetas que señala Jensen pueden percibirse en la entrevista brindada por Urbina. A través de ésta se mostrará cómo, desde territorios lejanos, la voz y el testimonio escrito ${ }^{3}$ se convierten en vía de los "ecos" que expresan al "actor, testigo y víctima".

\section{Eduardo Urbina Ayala entre la coyuntura del golpe de Estado de Honduras en 2009 y la "exclusión institucionalizada"}

Respecto a los elementos que motivan al exilio, sean estos políticos, culturales o socioeconómicos, Sznajder y Roniger apuntan que son sintetizados por la exclusión institucionalizada: "una situación de marginación de quienes se oponen a las políticas de los gobernantes -o se ven afectados por éstas- y, en consecuencia, se encuentran con que tienen que abandonar su país de origen o de residencia" (2013, p. 47). Los supuestos de Jensen (2011)

3 El entrevistado ha compartido con el autor de este trabajo una serie de poemas que escribió durante su paso por la cárcel. Éstos son analizados posteriormente. 
como los de Sznajder y Roniger (2013) son tomados en cuenta para reconstruir la dinámica de la represión y la experiencia exiliar de Urbina.

Para dar cuenta del exiliado en su carácter de "actor, testigo y víctima", he rastreado el activismo de Urbina en los años 2009, 2015 y 2017 - los cuales marcaron su carrera- para ubicar el origen de la persecución, producto de la "represión institucionalizada" a la que es sometido. Según su relato:

Días antes del golpe de Estado de 2009 yo había sido candidato a regidor, me contacta la Dirección Nacional del Partido que milito ${ }^{4}$ y me dicen que los apoye con los comandos antifraudes, jóvenes que iban a andar identificados con las siglas del Partido e iban [a] ingresar a cualquier centro de votación con o sin permiso de las autoridades para documentar el fraude electoral. Me desplazo al depto. de Yoro a una montaña. Pues, estoy el día de elecciones en esa montaña y, por medio de convocatoria, el presidente Zelaya, expresidente de Honduras, derrocado en el 2009, solicita apoyo a los procesos de lucha que se iban a dar para detener el fraude electoral. Me incorporo a las acciones y llego a INFOP, ${ }^{5}$ ahí se da el primer enfrentón con la policía, estamos hablando entre el 7 y 10 de noviembre. (E. Urbina, comunicación personal, 21 de octubre de 2018)

Urbina nos aproxima al desenlace de sus primeras acciones de activismo y militancia política. La alusión a la "documentación del fraude electoral" testifica su involucramiento en actividades de denuncia, que no cesarán aun encontrándose fuera de su patria. La coyuntura política en que Urbina se desenvuelve es el Golpe de Estado de Honduras de 2009:

Con fecha 28 de junio de 2009, efectivos de las Fuerzas Armadas irrumpieron en su casa de habitación y secuestraron al Presidente Constitucional de Honduras señor Manuel Zelaya Rosales. La captura del presidente se produjo sin que se presentara el mandato judicial co-

4 Se refiere al Frente Nacional del Resistencia Popular que surge ante el Golpe de Estado al gobierno de Manuel Zelaya en Honduras el día 28 de junio de 2009.

5 Instituto Nacional de Formación Profesional, centro de formación técnica ubicado en la capital hondureña. 
rrespondiente. Inmediatamente después fue trasladado a una base aérea desde donde fue llevado a Costa Rica. (Salgado, 2005, p. 77)

Hasta aquí se nos presenta el clima político y social en el que Urbina se ve inmerso. Respecto a Costa Rica como país receptor y los motivos para refugiarse en éste, argumentó:

Había estado trabajando en relaciones internaciones con las últimas operaciones y ya tenía contacto en la región mesoamericana y más o menos a nivel de América Latina, yo ya tenía opciones, sólo que la primera opción era Costa Rica, una, por estabilidad y, dos, porque aquí se respetaba el debido proceso y en aras de alguna persecución formal que se realizara en algún momento de acuerdo al proceso post salida del país. (E. Urbina, comunicación personal, 21 de octubre de 2018).

Las tierras costarricenses se presentaban como el mejor país de acogida debido al capital social trabajado previamente y la confianza en las protecciones que podría ofrecer a nivel jurídico.

Uno de los aspectos a considerar es la represión, más bien "exclusión institucionalizada" por parte del régimen que expulsa:

El núcleo central del exilio gira en torno al cierre de canales normativos de participación política, negociación y diálogo en el espacio político. La exclusión institucional implica el uso arbitrario del poder y la violencia en servicio de las metas políticas para quienes detentan el poder, así como la posible generalización de la violencia contra éstos. Quienes ostentan el poder ponen en práctica la exclusión, y proceden a utilizar la violencia de maneras arbitrarias. Es probable que se enfrenten a una oposición radicalizada, que persiguen, aprisionan, asesinan o destierran de la entidad política. (Sznajder y Roniger, 2013, p. 42)

Los supuestos teóricos enunciados permiten visualizar la experiencia y el trauma al que fue sometido Eduardo Urbina. En este sentido, uno de los recursos de limitación de libertades utilizados por el gobierno "golpista" fue el toque de queda. Principalmente la vigilancia e intimidación marcarán parte de la experiencia de Urbina: 
Pasa el 29 de noviembre, yo estoy en la colonia el Hato de en medio ${ }^{6}$ cuando decretan el toque de queda. Entonces yo comienzo a articular el regreso a mi casa. Y me llega un mensaje de WhatsApp en donde me muestran mi fotografía, mi nombre, mi número de teléfono y la dirección exacta de mi casa. Entre ellos mencionaban que yo estaba en disposición de cometer actos de terrorismo, inmediatamente llamo a las organizaciones de derechos humanos con los que yo desde hace años tenía comunicación, porque cabe mencionar que yo vengo siendo víctima de persecución política desde 2015 por mi militancia política-electoral, por mi militancia de movimientos sociales, por mi cercanía al movimiento ambientalista y movimiento campesino y por mi militancia en el movimiento estudiantil. (E. Urbina, comunicación personal, 21 de octubre de 2018)

Es precisamente este momento el que marcará el inicio de la etapa de persecución política que llevará a Eduardo Urbina a la clandestinidad en un primer momento y luego al destierro. Por su militancia y perfil político se convirtió en un objetivo para el aparato represivo: "en tales contextos, el exilio puede afectar a un rango cada vez más amplio de individuos sólo parcialmente conectados al dominio político, tales como intelectuales, profesionales, publicistas, académicos, líderes sindicales, estudiantes y activistas sociales" (Sznajder y Roniger, 2013, p. 42). Según su testimonio, Eduardo Urbina cumple con las condiciones que lo convierten en un sujeto "peligroso". La cronología vital y política ofrecida al inicio reafirma lo apuntado: "la primera vez que me acusan fue el 2015. En esa ocasión salgo para El Salvador por un mes. Hasta que se enfrió la situación volví a Honduras" (E. Urbina, comunicación personal, 21 de octubre de 2018).

El análisis de la política del exilio en América Latina, tal como se muestra en los estudios presentados en la introducción, permite constatar que: "la exclusión institucional implica el uso arbitrario del poder y la violencia en servicio de las metas políticas para quienes detentan el poder" (Sznajder y Roniger, 2013, p. 42). Este uso arbitrario del poder se ve reflejado en las tácticas implementadas por el país expulsor y su aparato represivo. En el caso de la persecución de Urbina, se manifestó de la siguiente manera:

6 Colonia popular de Tegucigalpa, capital de Honduras, que demostró su descontentó ante el Golpe de Estado de 2009. 
Paso a Costa Rica el día 11 de diciembre de 2017, en un primer momento yo iba a estar fuera por tres meses porque yo pensaba regresar en un lapso corto de tiempo. El día 15 de diciembre incendiaron un camión militar, yo estaba en un apartamento con tres dirigentes del Movimiento Estudiantil Universitario hondureño (MEU) y le digo a uno de ellos: "Sólo falta que me vayan a involucrar". Cuatro días después viajé a un cantón que se llama Heredia y del área metropolitana en Costa Rica, cuando me llega la orden de captura de la Interpol por uso de material de guerra, fabricación de explosivos e incendio agravado, delitos que a todas luces no había cometido, no estaba en el país cuando se cometieron. (E. Urbina, comunicación personal, 21 de octubre de 2018)

Dar cuenta de esa experiencia en la vida de Urbina implica recuperar su condición de víctima de un régimen que se valió de organismos internacionales, como la Interpol, para ejercer persecución y captura. En su defensa, el Comité de Familiares de Detenidos Desaparecidos en Honduras (COFADEH), a través de pruebas fehacientes, niegan la culpabilidad de Urbina: "Sacamos a Eduardo Urbina del país cinco días antes de que quemaran el camión militar", afirmó tal organización (Radio House, 2017).

Por su parte, la Federación Internacional de Derechos Humanos (FIDH) y el Observatorio para la Protección de los Defensores de Derechos Humanos, como miembros del Mecanismo de la Unión Europea para Defensores de Derechos Humanos, se pronunciaron en relación al caso, afirmando que "Urbina dejó Honduras para reubicarse temporalmente en Costa Rica ante los evidentes riesgos para su integridad física y psicológica de continuar en territorio hondureño"; además, se solicitaba a las autoridades hondureñas "tomar de manera inmediata las medidas más apropiadas para garantizar la seguridad y la integridad física y psicológica del Sr. Urbina" (Federación Internacional de Derechos Humanos, 2018).

La actuación de la FIDH y el Observatorio pone en escena un cuarto factor del exilio: la dimensión transnacional. Antes de la segunda mitad del siglo XX, el exiliado, el país expulsor y el país receptor eran los únicos elementos del formato del exilio temprano:

El formato del exilio sufrió una transformación fundamental durante la segunda mitad del siglo XX, una vez que la arena global entró a la 
ecuación como un cuarto factor. La arena global preocupada por el derecho humanitario internacional y la protección de los derechos humanos, se volvió cada vez más importante. (Sznajder y Roniger, 2013, p. 181)

Siguiendo el objetivo de intervenir para prevenir o remediar situaciones concretas de represión contra los defensores y defensoras de los derechos humanos, la Federación Internacional de Derechos Humanos (FIDH) y el Observatorio para la Protección de los Defensores de Derechos Humanos comunicaban:

El Observatorio acoge con satisfacción la liberación (28 de abril de 2018) del Sr. Eduardo Urbina y la decisión de las autoridades costarricenses de otorgarle el estatus de refugiado, pero sigue preocupado frente al proceso judicial relacionado a la quema del camión militar, que permanece en su contra en Honduras, en un intento de criminalizar su trabajo de defensa de derechos humanos. Asimismo, el Observatorio exige al Estado hondureño poner fin de manera inmediata a todo tipo de hostigamiento, incluyendo al nivel judicial, en contra del Sr. Eduardo Urbina y de todas las personas defensoras en Honduras. (Federación Internacional de Derechos Humanos, 2018)

La actuación internacional en relación al caso de Urbina deja en evidencia las redes que se configuran para defender casos de persecución, refugio y exilio. En esta dinámica, la creación del Alto Comisionado de las Naciones Unidas para los Refugiados (ACNUR), en 1949, marcó un hito.

Voz y palabra escrita. Las armas de denuncia desde el exilio Según Sznajder y Roniger (2013), el "exilio puede ser resultado de posiciones proactivas en la esfera política, así como de activismo en los dominios profesional, académico, intelectual, estudiantil o sindical, todos con implicaciones para la esfera pública" (p. 45).

El perfil de Urbina evidencia que su trayectoria es proactiva en la esfera política; basta recordar parte de su itinerario: forma parte del Frente Nacional Resistencia Popular; se ha enfilado en el Movimiento Patriótico en Resistencia; es miembro de la organización política Los Necios y del Partido Libertad y Refundación; también tiene participación en Izquierdas socialis- 
tas de Honduras, y fue integrante de la Mesa Estudiantes Indignados y del Movimiento Estudiantil Universitario (MEU). Aun desde otros territorios, el activismo político ha sido una constante en la vida de Urbina.

Aquí es pertinente traer a colación algunos elementos para el análisis del exilio. En primer lugar, está el país expulsor que motiva la deportación territorial con sus políticas de represión. En un segundo nivel, están los exiliados políticos en búsqueda de rutas; el clima político los desplaza hasta llegar al extranjero, donde pueden desarrollar o no actividad política. Un tercer factor es el país anfitrión o país receptor que, con sus políticas de asilo, acoge al individuo, pero a la vez limita su accionar (Sznajder y Roniger, 2013, p. 102).

Centrándonos en el segundo nivel de la dinámica, la búsqueda de rutas, y con base en el testimonio de Urbina, se pueden constatar aspectos como la integración social y la denuncia. Respecto a Costa Rica como país de destino y el ambiente que lo acogió, refiere:

Yo tenía contactos con varios partidos acá en Costa Rica, y acá la política de izquierda se mueve muy de cerca con todo el ámbito cultural. Entonces, si yo tenía entrada en uno, tenía entrada en el otro. Sumado a eso hay un hondureño que tiene un bar en Costa y es un bar que se parece mucho a Paradiso ${ }^{7}$ y desde que nos conocimos fue un clic y ahora que salí, pues, ha sido un espacio para desenvolverme un poco en la vida artística. Sí, es interesante el proceso porque no es lo mismo leer un discurso que leer un poema, me parece que el segundo es más contundente, el segundo pega más que el primero. ${ }^{8}$ (E. Urbina, comunicación personal, 21 de octubre de 2018)

El fragmento anterior nos permite adentrarnos en dos aspectos de la experiencia exiliar de Urbina, una vez instalado en tierras costarricenses. En primer lugar, el reto de la integración en el país que acoge. Se percibe que el ambiente fue "favorable"; las redes de solidaridad dieron viabilidad a su integración a la sociedad receptora. En segundo lugar, con la frase "y ahora que salí", refiere su paso por la prisión, en donde estuvo detenido en-

7 Centro cultural ubicado en la capital de Honduras.

8 El resaltado es propio para enfatizar el nuevo recurso utilizado por el exiliado: la escritura y lectura de poesía con fines de memoria y denuncia. 
tre el 10 de marzo y el 29 de abril de 2018 - cerca de veintiséis días: cinco en Nicaragua y diecinueve en Costa Rica-. La expresión "no es lo mismo leer un discurso que leer un poema" revela otra de sus facetas o experiencias: Urbina escribió poemas al interior de la cárcel.

La escritura de poemas desde la cárcel evidencia una predisposición al recuerdo y una lucha ante el olvido:

El acto de rememorar presupone tener una experiencia pasada que se activa en el presente, por un deseo o un sufrimiento, unidos a veces a la intención de comunicarla. No se trata necesariamente de acontecimientos importantes en sí mismos, sino que cobran una carga afectiva y un sentido especial en el proceso de recordar o rememorar. (Jelin, 2002, p. 26)

Podemos plantear que la intención comunicativa, el acto testimonial y el deseo de rememorar plantean al testigo salidas a veces necesarias o imprescindibles: la denuncia. En Urbina, ésta toma como vía la oralidad y la palabra escrita: "recordar como mandato imperioso" (Cassigoli, 1999, párr. 10).

Al consultar a Urbina sobre su experiencia en el encierro relata lo siguiente:

Jamás había sentido en la vida la desesperación así de forma tan cruda, situación porque yo no sabía qué estaba pasando, no sabía qué se estaba moviendo afuera, sólo sabía que, si llegaba a Honduras, me iba tocar un martirio. Llegué a un nivel de aceptación, estaba en disposición de cometer suicidio en el avión si a mí me extraditaban. Yo prefería morirme por mi propia mano en un avión a que me mataran las torturas de un régimen, eso dice cuán desesperado estaba. Aunque a mí el gobierno hondureño me pague lo que vaya a pagar en algún momento cuando interpongamos una demanda internacional, eso no me van a compensar. (E. Urbina, comunicación personal, $21 \mathrm{de}$ octubre de 2018)

El trauma, la violencia a la que fue sometido, las "pérdidas" se perciben en el relato: "el exilio no solamente es una cuestión política, es una cuestión psicológica, es una cuestión anímica, es una cuestión de salud, de muchas aristas a considerar" (E. Urbina, comunicación personal, 21 de oc- 
tubre de 2018). Se habla de pérdidas; no de ganancias. Aun así, el encierro o el desplazamiento crean posibilidades ante la necesidad de expresar; Urbina lo hizo a través de sus poemas y sus artículos de opinión (Urbina, 2018b). Ante la pregunta de qué quería expresar con sus letras, respondió:

Siempre en aras de seguir diciendo qué es lo que está pasando, porque si alguien tiene que salir de su país con las condiciones que yo salí o bajo las condiciones que han salido 15000 o 17000 de la población que ha salido en las últimas semanas, ${ }^{9}$ algo está mal y eso tenés que continuar denunciándolo si te queda voz para hacerlo, a mí por suerte me queda voz y hasta que esa voz no la callen yo voy a seguir denunciándolos. (E. Urbina, comunicación personal, 21 de octubre de 2018)

El ejercicio poético de Urbina, en tanto testimonio, busca dejar huellas de su experiencia. Es un acto introspectivo. Además, sus poemas denuncian el régimen que lo expulsó:

La voz no se calla porque vos la metas a la cárcel, para nada. Una voz no se calla, no me van a callar porque más allá de las actuaciones existen las palabras y si las palabras están plasmadas, aunque sea en un papel higiénico, hermano, pero están plasmadas, perduran. Yo escribí muchas veces por si a mí me extraditaban y al menos esos cuadernos pudieran llegar a mi familia. Lo hacía por mi familia y por mis amistades. (E. Urbina, comunicación personal, 21 de octubre de 2018)

Las experiencias exiliares, más allá de lo político, implican una dimensión existencial. Ante la amenaza del desarraigo, se existe en y a través de la escritura. Según Meyer (2009), en el testigo "hay una necesidad de hacer memoria, de generar recuerdos, de rememorar, preservar, en busca de la trascendencia: que no me olviden, que mi vida haya tenido sentido para los otro" (p. 21). Por su parte, Sánchez (2008) considera que "el miedo a no recordar, y también a no ser recordado, marca el periplo vital de los exiliados, convirtiendo en necesidad el dejar testimonio de su vida pasada" (p. 441).

9 El 12 de octubre de 2018, una caravana de 1600 migrantes salió de Honduras hacia Estados Unidos; posteriormente, se le sumaron guatemaltecos y salvadoreños. 
La "necesidad de memoria" y el "miedo a no ser recordado" no descarta la intención de proponerse como modelo ante futuras generaciones: "si yo no salía de ésta al menos quedaba como experiencia, como aprendizaje para próximas generaciones que, en el mejor de los casos, no les toque cosas como éstas [y], por si les toca vivir, pues, ya hay un precedente". (E. Urbina, comunicación personal, 21 de octubre de 2018)

El acto de memoria se sirve del recurso de la autobiografía. Ésta, según Artières (1998), constituye la práctica más acabada del archivo del yo, en la medida en que, recapitular su propia vida, el autor hace elecciones de determinados acontecimientos que, ordenados a lo largo de su narrativa, permitirá conocer el sentido que él deseó dar a su vida. La poesía de Eduardo Urbina, en calidad de testimonio, se convierte en el canal de la escritura autobiográfica, como se observa en el poema "Tu voz":

Salió mi murmullo de Honduras

Gané una voz libre

Se llevaron mi voz al Chipote

Mi voz dada esperanza

Se llevaron mi voz a Liberaría, volví a la vida ese día

Mi voz se volvió un símbolo de resistencia y de gallardía

Se llevaron mi voz al Centro de Aprehensión

Ahora desean destruirme

Se llevaron mi voz a Calle Blancos, bajo tierra 9 días

Cuanto más fuerte mi voz, más profundo me sepultan

Mi voz y mi murmullo partieron a Puntarenas

no sé si volverán aquí a mismo quedarán

Digo: Cuanto más fuerte mi voz, más profundo me sepultan

Sin contar las torturas e inminente muerte que me espera

En esa tierra que me vio nacer

Frontera CR, Frontera Nicaragua, Chipote, Frontera CR, Libera, Migración Central, Centro de Aprehensión, OIJ San José, OIJ Calle Blancos, Centro Penal Puntarenas, Migración Puntarenas y ahora sí puedo gritar LIBERTAD. (Urbina, 2018b) ${ }^{10}$

10 El resaltado es propio. 
Una voz que no calla, que no quiere callar; eso representa el caso de Urbina. El poema se convierte tanto en una "anatomía" de vivencias interiores como en una exteriorización de la "cartografía" de su destierro. Según Sánchez (2008),

no sólo se sueña con la tierra dejada, sino también con un tiempo irrecuperable que se identifica con el inmediatamente anterior a los sucesos, convulsos, que se produjeron la marcha del país. La salida suele justificarse por la implicación en algún tipo ideología o de forma política concreta, cuya defensa desde el extranjero va a ser asumida como proyecto vital. (p. 442)

Para resistir al desarraigo, Urbina recurre a la palabra. La palabra da cuenta de su condición y de sus aspiraciones. Libertad, esperanza, resistencia, gallardía, voz de denuncia, nostalgia por el terruño marcan sus convicciones ideológicas y políticas: "la mayor parte de los exiliados permanecen apegados, de manera consciente, con aquello que dejaron atrás" (Sznajder y Roniger, 2013, p. 53).

La antropóloga Cassigoli (1999) propone que la poesía es un acto de memoria: "como el oráculo es adivino del futuro, el aedo lo es del pasado, un hombre poseído por la memoria al componer versos recuerda. La poesía, identificada de este modo con la memoria. La memoria fue el antídoto del olvido" (párr. 25 ). Según esta propuesta, existe en Eduardo un "esfuerzo memorioso [...] [consagrado a] perpetuar el recuerdo del dolor que se ejerce como un no olvido" (párr. 31). El poema que sigue ilustra tal aseveración:

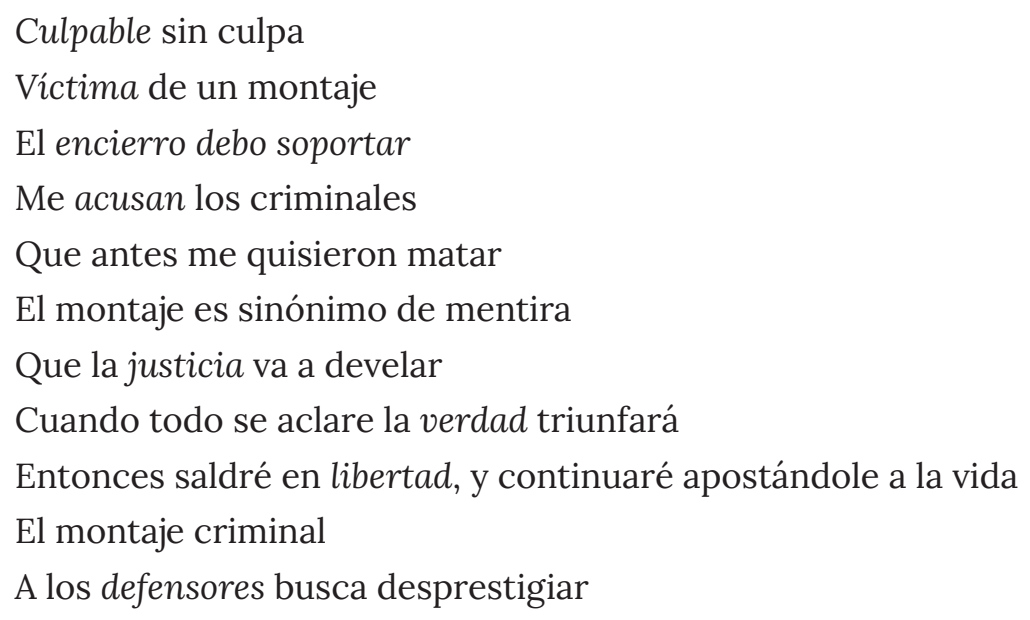


De víctimas a victimarios nos quieren igualar

Todo ello para buscar una especie de empate moral

El montaje fue bien planeado

Participaron los paramilitares

Y hasta instituciones del Estado

Por eso de manera injusta estoy encarcelado. (Urbina, 2018b) ${ }^{11}$

\section{Conclusión}

El fenómeno del exilio y su estudio permite repensar la vida política del continente. A través de su análisis, se puede revisar una de las tantas formas de hacer política en Latinoamérica.

La reconstrucción de la experiencia de Eduardo Urbina Ayala a través de su testimonio y de su poesía constata el potencial de otras fuentes como referentes para abrir el abanico teórico y metodológico en el estudio del exilio. A través de la historia oral, estudios de casos, historias de vida y biografías colectivas se puede analizar la violencia en el continente americano en sus distintas expresiones.

Tal como propone Meyer (2009), el investigador contribuye a "archivar la memoria":

Ante la sensación de un enorme vacío que obliga a seguir buscando diversos vestigios en el pasado y considerar, por, sobre todo, a los protagonistas anónimos de los procesos, aquellos que difícilmente legan su experiencia en forma escrita, muchos de ellos no cuentan con acervos documentales, con esos papeles que le dan en ocasiones validez y certidumbre a su propia historia. (p. 15 )

Acercarse al exilio desde las experiencias recuperadas a través del testimonio tiene como efecto la recuperación de la historia del desgarre. La "crisis continuada" en Honduras y sus consecuencias permite la apertura a la plurivocidad. El exilio de Eduardo Urbina ejemplifica las secuelas del golpe de Estado en Honduras de 2009 y la crisis actual. Su testimonio comunica el estatus de actor, testigo y víctima. Su palabra escrita es un acto de resistencia ante el olvido y un arma de denuncia.

11 El resaltado es propio. 
El caso de Urbina se presenta como un intento de ir hacia el sujeto y comunicar sus experiencias desde el microanálisis. Se abre paso, así, a narrativas que descentran las miradas a los hechos desde los grandes actores. Recuperar los testimonios y divulgarlos implica un ejercicio de archivar la memoria. Las violencias en las que está sumida Honduras reclaman la implementación de archivos de la palabra. Estos acervos, más que recuerdos del pasado reciente, pueden ser el sustento documental para la defensa de los derechos humanos y la creación de políticas públicas. Aunque esta práctica ha sido implementada sobre todo en el Cono Sur, Honduras no es ajena a la necesidad de memoria. El proyecto debe nacer de la sociedad civil, ya que a la estructura estatal le importan más los silencios y los olvidos.

\section{Referencias bibliográficas}

Argueta, M. (2008). Tiburcio Carías. Anatomía de una época. Guaymuras.

Artières, P. (1998). Arquivar a própria vida. Estudos Históricos, 1(21), 9-34. http://bibliotecadigital.fgv.br/ojs/index.php/reh/article/view/2061

Cassigoli, R. (1999). La memoria y sus relatos. Fractal, 13(3), 139-176. https:// www.mxfractal.org/F13cassi.html

Federación Internacional de Derechos Humanos (2018, 9 de mayo). Honduras: Criminalización, detención y liberación de Eduardo Urbina, defensor y miembro del MEU. https://www.fidh.org/es/temas/defensores-de-derechos-humanos/honduras-criminalizacion-detencion-y-liberacion-de-eduardo-urbina

Jelin, E. (2002). Los trabajos de la memoria. Siglo XXI.

Jensen, S. (2011). Exilio e historia reciente. Avances y perspectivas de un campo en construcción. Aletheia, 1(2), 1-21. http://www.memoria. fahce.unlp.edu.ar/art_revistas/pr.4806/pr.4806.pdf

Lastra, M. S. (2016). Volver del exilio: Historia comparada de las políticas de recepción en las posdictaduras de la Argentina y Uruguay [1983-1989]. Universidad Nacional de La Plata, Universidad Nacional de General Sarmiento, Universidad Nacional de Misiones.

Melgar Bao, R. (2018). Redes e imaginario de exilio latinoamericano en México y América Latina (1933-1940). Universidad Nacional Autónoma de México, Centro de Investigaciones sobre América Latina y el Caribe. 
Meyer, E. (2009). Memoria, olvido e historicidad. Revista del Programa de Historia Oral, (1), 13-28. http://ru.ffyl.unam.mx/handle/10391/3115

Monterrosa, L. (2019). La sombra del martinato: Autoritarismo y lucha opositora en El Salvador 1931-1945. Universidad Nacional Autónoma de México, Centro de Investigaciones Multidisciplinarias sobre Chiapas y la Frontera Sur.

Moreno Rodríguez, L. (2013). Exilio nicaragüense en México (1937-1947). Universidad Nacional Autónoma de México.

Radio House (2017, 21 de diciembre). COFADEH: "sacamos a Eduardo Urbina del país cinco días antes de que quemaran el camión militar". https:// www.radiohouse.hn/2017/12/21/cofadeh-sacamos-a-eduardo-urbina-del-pais-cinco-dias-antes-de-que-quemaran-el-camion-militar/

Rodríguez de Ita, G. (2001, octubre-diciembre). Exiliados guatemaltecos en México: Una experiencia recurrente. Pacarina del Sur. Revista de Pensamiento Crítico Latinoamericano. http://www.pacarinadelsur. com/_pacarina25/home/abordajes-y-contiendas/319-exiliados-guatemaltecos-en-mexico-una-experiencia-recurrente

Salgado, R. (comp.) (2005). Crisis institucional y golpe de Estado en Honduras. Universidad Pedagógica Nacional Francisco Morazán.

Sánchez, J. (2008). Memoria y literatura: Escritura desde el exilio. Lectura y signo: revista de literatura, 3(1), 437-453. https://dialnet.unirioja.es / servlet/articulo?codigo $=2735868$

Sierra, R. (2019). Honduras: del golpe de Estado de 2009 a la crisis continuada. Análisis Carolina, (16), 1-21. https://www.fundacioncarolina.es / wp-content/uploads/2019/08/AC_16.pdf

Sznajder, M. y Roniger, L. (2013). La politica del destierro y el exilio en América Latina. Fondo de Cultura Económica.

Urbina, E. (2018a, 19 de junio). Día Mundial de la Persona Refugiada. Delfino. https://delfino.cr/2018/06/dia-mundial-persona-refugiada/

Urbina, E. (2018b). Exilio: poemas de la cárcel. Archivo personal.

Waxenecker, H. (2019). Redes de poder politico-económico en Honduras: Un análisis post-golpe. Heinrich Böll Stiftung. https://sv.boell.org/ es/2020/03/26/redes-de-poder-politico-economico-en-honduras 